Airway hyperresponsiveness, remodeling and inflammation in infants with wheeze

\title{
Malmström, Kristiina
}

2020-05

Malmström , K , Lohi , J , Malmberg , L P , Kotaniemi-Syrjänen , A , Lindahl , H , Sarna , S , Pelkonen , A S \& Mäkelä , M J 2020 , ' Airway hyperresponsiveness, remodeling and inflammation in infants with wheeze ', Clinical and Experimental Allergy , vol. 50 , no. 5 , pp. 558-566 . https://doi.org/10.1111/cea.13598

http://hdl.handle.net/10138/327778

https://doi.org/10.1111/cea.13598

unspecified

acceptedVersion

Downloaded from Helda, University of Helsinki institutional repository.

This is an electronic reprint of the original article.

This reprint may differ from the original in pagination and typographic detail.

Please cite the original version. 
DR KRISTIINA MALMSTRÖM (Orcid ID : 0000-0001-9299-8434)

Article type : Original Article-Asthma and Rhinitis

Airway hyperresponsiveness, remodeling and inflammation in infants with wheeze

Short running title: Airway responsiveness and remodeling in wheeze

Manuscript words 3430; table count 3; figure count 3 series, altogether 7 figures

Kristiina Malmström ${ }^{1}$, Jouko Lohi², L. Pekka Malmberg ${ }^{1}$, Anne Kotaniemi-Syrjänen ${ }^{1}$, Harry Lindahl ${ }^{3}$, Seppo Sarna ${ }^{4}$, Anna S. Pelkonen1, Mika J. Mäkelä1

1. MD, PhD, Skin and Allergy Hospital, University of Helsinki and Helsinki University Hospital, PO Box 160, Fl-00029 Helsinki, Finland.

2. MD, PhD, Dept. of Pathology, University of Helsinki and Helsinki University Hospital, PO Box 21, Fl-00014 Helsingin yliopisto, Helsinki, Finland

3. MD, PhD, Children's Hospital, University of Helsinki and Helsinki University Hospital, PO Box 281, FI-00029 Helsinki, Finland.

4. PhD, Dept. of Public Health, University of Helsinki, PO Box 30, 00271 Helsinki, Finland.

Correspondence and reprint requests to: Kristiina Malmström, MD, PhD

Skin and Allergy Hospital, Helsinki University Hospital

PO Box 160, FI-00029 Helsinki, Finland

E-mail: kristiina.malmstrom@fimnet.fi; Tel: +358 505282266; Fax: +358 947186560

\section{Abstract}

This article has been accepted for publication and undergone full peer review but has not been through the copyediting, typesetting, pagination and proofreading process, which may lead to differences between this version and the Version of Record. Please cite this article as doi: 10.1111/CEA.13598

This article is protected by copyright. All rights reserved 
Background: The relationship of airway hyperresponsiveness to airway remodeling and inflammation in infants with wheeze is unclear.

Objective: To investigate airway hyperresponsiveness, remodeling and inflammation in infants with wheeze and troublesome breathing.

Methods: Inclusion criteria: full-term, 3-23 months of age; doctor diagnosed wheeze and persistent recurrent troublesome breathing; without obvious structural defect, suspicion of ciliary dyskinesia, cystic fibrosis, immune deficiency or specified use of corticosteroids. Airway hyperresponsiveness (AHR) was evaluated by performing a methacholine bronchial challenge test combined with whole body pletysmography and rapid thoracoabdominal compression. Endobronchial biopsies were analyzed for remodeling (thickness of reticular basement membrane and amount of airway smooth muscle) and for inflammation (numbers of inflammatory cells). Correlation analyses were performed.

Results: Forty-nine infants fulfilled the inclusion criteria for the present study. Median age was 1.06 years (IQR 0.6; 1.5). Lung function was impaired in 39/49 (80\%) children, at the median age of 1.1 years. Methacholine challenge was successfully performed in 38/49 children. Impaired baseline lung function correlated with AHR ( $p=0.047$, Spearman). In children with the most sensitive quartile of AHR, the percentage of median bronchial airway smooth muscle \% and the number of bronchial mast cells in airway smooth muscle were not significantly higher compared to others $(p=0.057$ and 0.056 respectively). No association was found between AHR and thickness of reticular basement membrane or inflammatory cells. Only a small group of children with both atopy and AHR (the most reactive quartile) had thicker airway smooth muscle area than non-atopics with AHR $(p=0.031)$.

Conclusions \& Clinical Relevance: These findings don not support the concept that AHR in very young children with wheeze is determined by eosinophilic inflammation or clearcut remodeling although it is associated with impaired baseline lung function. The possible association of increased airway smooth muscle area among atopic children with AHR remains to be confirmed. 


\section{Abbreviations:}

AHR

ASM

FRC

$\lg E$

IQR

PD40 V'maxFRC

RBM

sGaw

SPT

V'maxFRC
Airway hyperresponsiveness

Airway smooth muscle

Functional residual capacity

Immunoglobulin E

Interquartile range

Provocative dose of methacholine causing a $40 \%$ fall in V'maxFRC

Reticular basement membrane

Specific airway conductance

Skin prick test

Maximal airflow at functional residual capacity

\section{Introduction}

Airway hyperresponsiveness (AHR) together with airway inflammation are considered as hallmarks of asthma leading to symptoms. On the other hand, airway remodeling is a characteristic feature of asthma, characterized by structural changes such as epithelial injury, thickening of reticular basement membrane (RBM), increased airway smooth muscle (ASM) mass, goblet cell hypertrophy and hyperplasia, and increased angiogenesis (1). The relationship between inflammation and remodeling is controversial. It is unknown in children if repeated airway inflammation precedes remodeling changes (2).

The mechanisms of airway responsiveness are complex. AHR has been associated with chronic allergen exposure, reduced airway caliber, airway inflammation (metachromatic cell degranulation, eosinophils, lymphocytes), neural mechanisms (3), and changes in airway wall thickness (increased ASM) (4). There are also several factors that oppose excessive airway narrowing such as lung elastic recoil, airway-parenchymal interdependence and breathing dynamics (5). AHR early in life has been linked with atopy (6), wheeze (6), tobacco-smoke exposure (7), lower respiratory tract infections $(6,8)$, reduced baseline lung function $(6,9)$, altered lung function later in life (10) and 
asthma (11). Birth-cohort studies suggest that association between AHR and asthma is stronger in early childhood than at school-age or in adulthood, and AHR is driven by different mechanisms in the neonatal period and in later life (11).

Thickening of RBM in children with recurrent lower respiratory track symptoms or severe wheeze seems to evolve after 2-3 years of age (12,13). Hypertrophy of ASM was found at 6 years of age in severe corticosteroid dependent asthma (14) and in one study in children with mild to moderate asthma from seven years of age forward (15). Thickness of RBM and ASM area increased with age (median 3-10 years) in children with severe recurrent wheeze, yet these remodeling findings were not related to inflammatory cell counts (16).

In adults with asthma, increased ASM mass was shown to correlate with AHR to histamine and degree of eosinophilic inflammation with AHR to acetylcholine (4). It is unclear whether (increased) ASM is the key player of AHR and what is the role of other structural changes of the airway related to remodeling or inflammation in very young children with wheeze.

In this observational study, we aimed to investigate the association between AHR and airway remodeling and inflammation, derived from carina biopsies, in infants with wheeze. 


\section{Methods}

\section{Study subjects}

Inclusion criteria: full-term infants (>37 weeks of gestation), aged 3 months to 23 months, with a history of physician-diagnosed wheeze and persistent (daily to weekly) recurrent troublesome breathing. Exclusion criteria: a need for inhaled corticosteroids (ICS) within 8 weeks prior to the first visit; a cumulative life-time systemic prednisolone use for more than 3 days at a dose of $2 \mathrm{mg} / \mathrm{kg}$, or an equipotent dose of another systemic corticosteroid or life-time ICS use more than 4 weeks; respiratory infection in the 14 days preceding the lung function measurement; any obvious structural defect; any suspicion of ciliary dyskinesia, cystic fibrosis or immune deficiencies. Approval for this study was obtained from Ethics Committee for Children's Hospital of Helsinki University Hospital. Written informed consent was obtained from the guardians of the children.

\section{Study design}

Between September 2004 and September 2012, 730 consecutive infants and very young children younger than 24 months of age referred to the Department of Allergy, Helsinki University Hospital, a tertiary pediatric center, for the measurement of lung function because of recurrent wheeze or troublesome breathing. Functional residual capacity (FRC) and specific airway conductance (sGaw) were measured using infant body pletysmograph and maximal airflow at functional residual capacity (V'maxFRC) was measured using rapid thoracoabdominal compression technique (6). Lung function was regarded abnormal when any of the following was detected: z-score of V'maxFRC $<-1.65$ or z-score sGaw <-1.65. Bronchial challenge test with methacholine was performed.

As part of their clinical assessment, 72 children underwent bronchoscopy after lung function measurements. Bronchoscopy was performed to exclude structural airway abnormalities, such as subglottic stenosis, laryngo-, trachea-, or bronchomalacia, and other diagnoses, such as foreign body inhalation or mucus plugging. Bronchoscopy with endobronchial biopsy was performed under general anesthesia with a $5.5 \mathrm{~mm}$ flexible bronchoscope using $1.8 \mathrm{~mm}$ disposable radial jaw biopsy forceps. For the youngest children, endobronchial biopsies were taken with a 3.5-mm rigid bronchoscope, using biopsy forceps (No. 10378L; Karl Storz, GmbH and Co., Tuttingen, Germany). One or two 
biopsies were taken from the main carina and they were investigated for parameters of remodeling (thickness of RBM and ASM \%) and inflammation (inflammatory cells). If a clear structural airway anomaly was identified, patients were excluded from the present study. Thorax X-ray and skin-prick tests (SPT) were performed. Blood specimens were obtained for analysis of blood eosinophil count, serum total immunoglobulin $E(\lg E)$ levels and alpha-1 antitrypsin, and stool was analysed for elastase.

\section{Atopy}

Atopy of the patients was defined as a positive SPT result to food or aeroallergens. Sensitization was tested to egg white, cow's milk, wheat, soy bean, cod, shrimp, peanut, birch pollen, timothy grass pollen, dog epithelial dander, cat epithelial dander and Dermatophagoides pteronyssinus. Atopy of the parents or siblings was considered to be present if atopic eczema, allergic rhinoconjunctivitis or food allergy were reported.

\section{Methacholine challenge}

The dosimetric methacholine challenge test was performed as described previously (6). A calibrated nebulizer (Salter Labs 8900, Arvin, CA) was connected to an automatic, inhalation-synchronized dosimeter (Spira Electro II, Spira Respiratory Care Center Ltd, Finland). By calculating the number of breaths with nebulized methacholine, a dosage scheme with four non-cumulative dose steps was delivered $(0.1,0.3,0.9$ and $1.8 \mathrm{mg})$, with V'maxFRC being recorded after each dose. There were two endpoints in the challenge test; a fall of $40 \%$ or more in V'maxFRC or reaching the maximal dose of methacholine.

The provocative dose of methacholine causing a 40\% fall in V'maxFRC (PD40 V'maxFRC) was determined from the dose-response curves. In cases where the maximal dose was reached and PD40 V'maxFRC could not be determined from the doseresponse curves, for statistical purposes, PD40 V'maxFRC was defined as twice the highest dose of methacholine, $3.60 \mathrm{mg}$. The PD40 V'maxFRC values were divided in quartiles and patients with PD40 V'maxFRC values in the most sensitive quartile were regarded as individuals with increased AR. The cut-off value of PD40 V'maxFRC for normal vs. AHR was the highest PD40-value among the individuals in the most sensitive quartile. 
Oxygen saturation and heart rate were continuously monitored with a pulse oximeter (Biox 3700e, Ohmeda, Louisville, KY). Following the challenge test, the children received inhaled salbutamol $(0.6 \mathrm{mg}$ ) (Ventoline Evohaler $0.1 \mathrm{mg} / \mathrm{dos}$ ) via Nebuchamber.

\section{Biopsy processing}

Carinal biopsies were processed and fixed in formalin before paraffin embedding, microscopic slide preparation and staining. The persons assessing biopsies were blinded to the lung function results.

RBM measurement: Thickness of the reticular basement membrane was measured from Herovici stained sections. The whole subepithelial basement membrane was photographed using 20x magnification and measure points were randomly selected using grid-overlay method (17). Thickness of the RBM layer was measured by hand where it intersected the grid. Individual measurements varied in number from 30 to 170 .

ASM measurement: To measure the amount of ASM, the tissue slides stained for smooth muscle actin were photographed. Total subepithelial area was first determined by manually selecting the whole subepithelial biopsy area from photograph and calculating this area with ImageJ program. To identify the proportion of airway smooth muscle, ASM bundles were first roughly outlined by hand. Brown immunostained pixels within this selected area corresponding to smooth muscle were then identified by passing the photograph through a color-treshold filter and converting all brown pixels to black and all other pixels to white. The area of black pixels was then calculated, the airway area was selected and converted to black and the area calculated using the calibrated scale as described before (17). The amount of smooth muscle is expressed as a percentage of subepithelial area of the biopsy (ASM\%).

Inflammatory cells: Inflammatory cells were identified in mucosa and submucosa by immunostaining using antibodies: T-lymphocytes (CD3, 2GVG Ventana, Roche), Blymphocytes (CD20, L26 Ventana, Roche), plasma cells (CD138, B-A38, Ventana, Roche), mast cells (CD117, polyclonal, Dako), and macrophages (CD163, 10D6, Novocastra). Eosinophils were counted from hematoxylin-eosin slides. Neutrophilic 
leukocytes and eosinophils were stained with CD15 (MMA, Roche) and identified based on morphology. Results were expressed as number of cells/subepithelial area $\left(1 / \mathrm{mm}^{2}\right)$.

\section{Statistical analysis}

Mann-Whitney's test was used to compare the results between the groups and Wilcoxon's test within the groups for non-normal data and Kruskal-Wallis test for subgroup analysis. Comparison of means with normally distributed variables was performed with ANOVA and t-test. The associations between histological and clinical findings were evaluated with Spearman's correlations and Chi²-tests. Two-sided p-values $<0.05$ were considered statistically significant. 


\section{Results}

\section{Subjects}

Forty-nine infants fulfilled the inclusion criteria for the present study. Fourteen infants were excluded due to macroscopic structural changes and nine due to the use of corticosteroids. Median age was 1.06 years (IQR $0.6 ; 1.5)$ and the demography is shown in Table 1. Inspection bronchoscopy revealed swelling of mucus membranes in 11, increased mucus in six, and minor malacia in four (subglottal one, tracheal two, bronchial one) children.

\section{Lung function and $A H R$}

Lung function and methacholine challenge test results are shown in Table 2. V'maxFRC was reduced (z-score < -1.65) in 24/49 $(49 \%)$ with median V'maxFRC z-score of -1.5 (interquartile range (IQR) -2.3; -0.5), and sGaw was reduced (z-score <-1.65) in 29/49 $(59 \%)$ children, and taken these together, lung function was regarded abnormal in 39/49 $(80 \%)$. Methacholine challenge was successful in 38/49 children. Severe peripheral obstruction, low oxygen saturation or unstable V'maxFRC measurements at the baseline hindered bronchial challenge testing in the rest of the infants. Median V'maxFRC was significantly higher for those with than without the methacholine challenge [z-score -1.3 (IQR -2.43; -1.25) vs z-score -2.3 (IQR -3.0; -2.3), p=0.002; Mann-Whitney test]. During the methacholine provocation, median changes in V'maxFRC and oxygen saturation were $-52 \%$ and $-3 \%$, respectively.

The cut-off value of PD40 V'maxFRC for the most sensitive quartile was found to be $\leq 0.21 \mathrm{mg}$ methacholine. Baseline V'maxFRC was the only lung function parameter that showed a correlation with AR ( $r=0.392, p=0.015$; Spearman), Figure 1A. However, baseline V'maxFRC was not significantly lower among the most reactive quartile compared to the rest of the children, Figure 1B. Neither atopy nor any other clinical feature or exposure for tobacco was associated with AHR.

\section{Remodeling and inflammation}


Remodeling and inflammatory cell results from 49 children are seen in Table 3 . The thickness of RBM varied between 2.9 and $5.2 \mu \mathrm{m}$ with a median of $4.0 \mu \mathrm{m}$. The percentage of median bronchial ASM mass was $10.6 \%$, with maximal percentage of $25 \%$. Bronchial ASM area \% had a negative association with RBM ( $r=-0.301, p=0.038$; Spearman). Bronchial eosinophils were seen in 21 (43\%) children but they were mainly detected occasionally: $0-1$ cells $/ \mathrm{mm}^{2}$ in 7 children; 2 - 5 cells $/ \mathrm{mm}^{2}$ in 10 children; >5 cells $/ \mathrm{mm}^{2}$ in 4 children. T-lymphocytes were abundant, followed by macrophages, Blymphocytes and plasma cells. Mast cells were found in all but one child. Neutrophils were detected in a wide range.

\section{Associations between AHR or lung function and remodeling or inflammation}

The median bronchial ASM \% in subepithelial area did not correlate significantly with AHR, Figure 2A. Bronchial ASM area was higher in children with the most sensitive AHR (methacholine PD40 $\leq 0.21 \mathrm{mg}$ ) versus the rest although the difference did not reach the level of statistical significance $(p=0.056$; t-test). Even when the patients were grouped in quartiles according to the AHR, bronchial ASM area was not significantly associated with AHR ( $p=0.071$; ANOVA) Figure 2B. A subgroup of children with both atopy and increased AHR (the most reactive quartile) had thicker ASM area $(p=0.031$; Kruskal-Wallis) than non-atopics with increased AHR, Figure 2B. Thickness of RBM was not associated with $\operatorname{AHR}(p=0.61$; t-test), Figure 2C. The number of bronchial mast cells in ASM did not correlate significantly with AHR ( $p=0.056$; t-test), Figure $2 D$. There were no associations between other inflammatory cells and AHR.

The early presence of bronchial eosinophils was associated with lower baseline V'maxFRC ( $p=0.029, r=-0.318$; Spearman), Figure 3. No other associations between abnormal lung function and remodeling or inflammatory cells were found.

\section{Associations between bronchial inflammatory cells and remodeling}

Bronchial macrophages were associated significantly with $\mathrm{T}$ - and $\mathrm{B}$-lymphocytes and neutrophils $(r=0.488$ and $p=0.003 ; r=0.520$ and $p=0.001 ; r=0.466$ and $p=0.004$;

Spearman, respectively). In addition, neutrophils were significantly associated with $\mathrm{T}$ - and B-lymphocytes ( $r=0.478$ and $p=0.001 ; r=0.462$ and $p=0.001$; Spearman, respectively). 
Interestingly, $\mathrm{T}$ - and $\mathrm{B}$-lymphocytes had negative association with bronchial ASM area \% ( $r=-0.369$ and $p=0.012 ; r=-0.346$ and $p=0.017$; Spearman, respectively). The remodeling markers did not have any correlations with the inflammatory cells.

\section{Discussion}

We provide the first observation that increased airway hyperresponsiveness under the age of two years is poorly explained by airway remodeling and inflammation in children with early onset of doctor diagnosed wheeze and recurrent troublesome breathing. While AHR associated significantly with impaired baseline lung function, it was not associated with increased ASM \%, thickness of RBM or numbers of inflammatory cells.

\section{Lung function and $A H R$}

As expected, decreased baseline lung function as expressed by V'maxFRC was found to be associated with AHR. This was true when V'maxFRC was considered and agrees with a previous finding in symptomatic children of same age (6). The definition of AHR in this age group or at preschool age is arbitrary, since the results are method-specific and no normative values are available for ethical reasons. Like wise in the present study, for ethical reasons a healthy control group was not included and therefore AHR comparisons were performed within the cohort. We found that PD40 V'maxFRC $0.21 \mathrm{mg}$ of methacholine was the cut-off level for the most sensitive quartile. The used cut-off line of $0.21 \mathrm{mg}$ was lower than that in our previous study (PD40 V'maxFRC $0.9 \mathrm{mg}$ ) (6) which was associated with atopy and physician-diagnosed wheeze. Lower provocative dose cut-off values in AHR determination are linked with a higher specificity and a positive predictive value for asthma (18).

Airway narrowing or AHR may exist temporarily in symptomatic children related with genetic and developmental factors in the first years of life (19). AHR at an early age $(<2$ years) has been linked with exposure of tobacco (7) and atopy (6). Even though smoking was present in $1 / 3$ of the families in the present study, AHR was not associated with tobacco exposure, neither to atopy.

\section{Remodeling}


Repeated bronchoconstriction may stimulate remodeling such as increased ASM independently of inflammation (20). In the present study, we found that ASM area was similar to that $(10 \%)$ in our previous study in symptomatic infants (21) but healthy control groups are missing in both cohorts. Instead, ASM was increased in preschoolers developing asthma compared to non-asthmatics at school age (12.7 vs. 6\%) (22). Similarly, ASM was increased in preschool wheezers and in severe asthma at school age $(10 \%$ and $16 \%)(16)$. In children with severe poorly controlled asthma (5-14 yrs) larger ASM thickness was found among those with persistent obstruction pattern than without (24\% vs. $15 \%$ ) and correlated with the level of obstruction (23). In children and adolescents with fatal asthma, ASM area in large airways was clearly increased in $1 / 3$ ( $28 \%$ vs. $12 \%$ ) studied by the same method than in the present study (17).

The increase of RBM thickness in severe wheeze (16) and in fatal asthma (17) in children and adolescents has been found to correlate with age. The current RBM findings are consistent with our previous findings (12) that RBM is not clearly thickened at this early age, not even in the presence of AHR.

\section{Association between AHR and remodeling}

Our findings suggest that AHR is not strongly associated with remodeling, i.e. increased thickness of RBM or bronchial ASM mass in this very young age group with wheeze and persistent recurrent troublesome breathing. A positive association of AHR with ASM was found only in a subpopulation of children with atopy. As remodeling features have been described in older children with established asthma it is possible that only those infants with later asthma may actually show the same features and hence, some association with AHR, the cornerstone of asthma. Our findings among these few atopic children may be indicative for this. In severe adult asthma, ASM thickness was inversely correlated with AHR to histamine reflecting airway remodeling, particularly ASM hypertrophy (4). Even in adult subjects with a history of asthma, greater ASM mass contributed to exaggerated in vitro airway narrowing of bronchial segments to acetylcholine (24). In a recent study in mice, the authors found an association between the thickness of ASM and AHR which was potentified in the presence of allergy (25). The mechanisms of the association between ASM thickening and AHR are complex. Thickness of ASM may be related to 
excess of airway narrowing during bronchoconstriction. Increased ASM mass amplifies the effect of smooth muscle shortening and the ability of the airways to generate radial force during constriction, which is further promoted by uncoupling of ASM from parenchymal recoil by remodelling (26). On the other hand, stiffening of the airway due to remodeling such as viscous and elastic loads as well as ASM contractility with the possible "fixed" nature of airway reactivity may be protective against AHR (27).

\section{Association between AHR and inflammation}

Variable airflow obstruction in adult asthma was associated with infiltration of mast cells in ASM (28). In contrast, the numbers of mast cells in ASM were not significantly higher in children with AHR in the present study. The proportion of the number of mast cells compared to the total number inflammatory cells in the present study was three-fold bigger compared to that in our previous study but the analyses were done with different techniques (12).

Bronchial eosinophils are detectable among severe asthmatics from preschool age upwards (13) and are present in severe $(14,29)$ and fatal childhood asthma (17). As well, the infiltration of bronchial eosinophils at preschool age were higher in children who continued to have severe exacerbations at school age (30). In the present study bronchial eosinophils were detected mostly occasionally strengthening the earlier findings of the rarity of eosinophilic inflammation at this very young age $(12,16)$. That said, the numbers of mast cells in ASM were not significantly higher in children with AHR. However, whether these very early solitary bronchial eosinophils reflect incipient inflammation predicting later AHR or asthma, remains to be studied in a longitudinal setting. Notably, in the present study the presence of bronchial eosinophils was associated with reduced lung function as expressed by V'maxFRC, which suggest significance of even small numbers of bronchial eosinophils in infants with wheeze.

In the present study, $\mathrm{T}$ - and B-lymphocytes had a negative association with bronchial ASM area \%. Maybe there was more submucosal connective tissue containing lymphocytes when the amount of ASM was smaller. The distribution of other inflammatory cells was comparable to our previous findings (12). 


\section{Location of the biopsy}

Since rigid bronchoscopy was routine clinical practice by the time this study was started, the location of biopsy was naturally main carina, similarly as in our earlier cohort $(12,21)$. However flexible bronchoscopy became the praxis, but the location of biopsy remained the same during the study. In many other recent studies biopsies were taken at the third to fourth generation of segmental bronchi $(13,16,22)$. The carinal site of biopsy may affect the findings, both for remodeling and inflammation and their correlation with AHR and peripheral airflow limitation. The importance of association between ASM and increased AHR among the most reactive quartile of children with atopy may highlight more persisting disease.

\section{Weaknesses}

We expect that the final group of infants is not totally representative of the overall population of infants referred, mainly due to clinical indications for bronchoscopy. Potential heterogeneity of the included patients may limit the results. The heterogeneity of the study population may partly be explained by the young age and thereof short history of the patients. Measurements of AHR are challenging in infants and in some cases AHR measurements were not possible due to marked peripheral obstruction at baseline and therefore AHR measurements were successful not in all but in four fifth of children. We acknowledge that the subgroup of atopic children with association between AHR and ASM is small. We also acknowledge that, for ethical reasons, biopsies from healthy controls are missing. The same limitation, i.e. a lack of a contol group, applies for the cut-off values used in methacholine provocation.

\section{Conclusions}

In summary, our findings do not support the concept that AHR in very young children with wheeze and troublesome breathing is determined by eosinophilic inflammation or clearcut remodeling. The possible association of increased ASM among atopic children with AHR remains to be confirmed in further studies. 


\section{Acknowledgements}

We thank Pauli Lohi for expert help in quantification of smooth muscle area and RBM thickness. This work was supported by the Nummela Sanatorium Foundation; the Finnish Society of Allergology and Immunology; Foundation for Pediatric Research; and Sigrid Juselius Foundation. 


\section{References}

1. Jeffery PK. Remodeling in asthma and chronic obstructive lung disease. Am J Respir Crit Care Med 2000;164:S28-S38.

2. Castro-Rodriguez JA, Saglani S, Rodriguez-Martinez CE, Oyarzun MA, Fleming L, Bush A. The relationship between inflammation and remodeling in childhood asthma: A systematic review. Pediatric Pulmonol 2018;53:1-12.

3. Cockcroft DW, Davis BE. Mechanisms of airway hyperresponsiveness. J Allergy Clin Immunol 2006;118:551-9.

4. Trugisawa N, Oshikata C, Tsuburai T, Saito H, Sekiya K, Tanimoto H, Takeichi S, Mitomi H, Akiyama K. Bronchial hyperresponsiveness to histamine correlates with airway remodeling in adults with asthma. Respir Med 2010;104:1271-7.

5. Lauzon AM, Martin JG. Airway hyperrresponsiveness; smooth muscle as the principal actor. F1000Research 2016, 5(F1000 Faculty Rev):306 last updated:25 SEP 2018.

6. Kotaniemi-Syrjänen A, Malmberg LP, Pelkonen AS, Malmström K, Mäkelä MJ. Airway responsiveness: associated features in infants with recurrent respiratory symptoms. Eur Respir J 2007;30:1150-7.

7. Young S, Le Souef PN, Geelhoed GC, Stick S, Turner KJ, Landau LI. The influence of a family history of asthma and parental smoking on airway responsiveness in early infancy. N Engl J Med 1999;324:1168-73.

8. Chawes B, Poorisrisak P, Johnston SL, Bisgaard H. Neonatal bronchial hyperresponsiveness precedes acute severe viral bronchiolitis in infants. J Allergy Clin Immunol 2012;130:354-61.

9. Palmer LJ, Rye PJ, Gibson NA, Burton PR, Landau LI, Le Souef PN. Airway responsivess in early infancy predicts asthma, lung function and respiratory symptoms by school age. Am J Respir Crit Care Med 2001;163:37-42.

10. Delacourt C, Benoist MR, Le Bourgeois M, Waernessyckle S, Rufin P, Brouard JJ, de Blic J, Scheinmann P. Relationship between bronchial hyperresponsiveness and impaired lung function after infantile asthma. PLoS One 2007;2(11):e1180.

11. Bisgaard $\mathrm{H}$, Jensen $\mathrm{SM}$, Bonnelykke $\mathrm{K}$. Interaction between asthma and lumg function growth in early life. Am J Respir Crit Care Med 2012;185:1183-9. 
12. Saglani S, Malmström K, Pelkonen AS, Malmberg LP, Lindahl H, Kajosaari M, Turpeinen M, Rogers AV, Payne DN, Bush A, Haahtela T, Mäkelä MJ, Jeffery PK. Airway re-modeling and inflammation in symptomatic infants with reversible airflow obstruction. Am J Respir Care Med 2005;171:722-7.

13. Saglani S, Payne DN, Zhu J, Wang Z, Nicholson AG, Bush A, Jeffery PK. Early detection of airway wall remodeling and eosinophilic inflmammation in preschool wheezers. Am J Respir Crit Care Med 2007;176:858-64.

14. Jenkins HA, Cool C, Szefler SJ, Covar R, Brugman S, Gelfand EW, Spahn JD. Histology of severe childhood asthma: a case series. Chest 2003;124:32-41.

15. Regamey N, Ochs M, Hilliard TN, Mühlfedl C, Cornish N, Fleming L, Saglani S, Alton EW, Bush A, Jeffery PK, Davies JC. Increased airway smooth muscle mass in children with asthma, cystic fibrosis, and non-cystic fibrosis bronchiesctasis. Am J Respir Crit Care Med 2008;177:837-43.

16. Lezmi G, Gosset P, Deschildre A, Abou-Taam R, Mahut B, Beydon N, de Blick J. Airway remodeling in preschool children with severe recurrent wheeze. Am J Respir Crit Care Med 2015;192:164-71.

17. Malmström K, Lohi J, Jahnsen FL, Sajantila A, Kajosaari M, Sarna S, Mäkelä MJ. Immunohistology and remodeling in fatal pediatric asthma. Respir Res 2017;18:94.

18. Cockcroft DW. Direct challenge Tests. Airway hyperresponsiveness in sthma: its measurements and clinical significance. Chest 2010;138:18S-24S.

19. Cox DW, Mullane D, Zhang GC, Turner SW, Hayden CM, Goldblatt J, Landau LI, Le Souëf PN. Longitudinal assessment of airway responsiveness from 1 month to 18 years in the PIAF birth cohort. Eur Respir J 2015;46:1654-61.

20. Grainge CL, Lau LCK, Ward JA, Dulay V, Lahiff G, Wilson S, Holgate S, Davies $\mathrm{DE}$, Howarth $\mathrm{PH}$. Effect of bronchoconstriction on airway remodeling in asthma. $\mathrm{N}$ Engl $\mathrm{J}$ Med 2011;364:2006-15.

21. Malmström K, Malmberg LP, O’Reilly, Lindahl H, Kajosaari M, Saarinen KM, Saglani S, Jahnsen FL, Bush A, Haahtela T, Sarna S, Pelkonen A, Mäkelä MJ. Lung function, airway remodeling, and inflammation in symptomatic infants: Outcome at 8 years. Ann Allergy Asthma Immunol 2015;114:90-6. 
22. O’Reilly R, Ullman N, Irving S, Bossley CJ, Sonnappa S, Zhu J, Oates T, Banya W, Jeffery PK, Bush A, Saglani S. Increased airway smooth muscle in preschool wheezers who have asthma at school age. J Allergy Clin Immunol 2013;131:1024-32.

23. Tillie-Leblond I, de Blic J, Jaubert F, Wallaert B, Scheinmann P, Gosset P. Airway remodeling is correlated with obstruction in children with severe asthma. Allergy 2008;63:533-41.

24. Noble PB, Jones RL, Cairncross E, Elliott JG, Mitchell HW, James AL, McFawn PK. Airway narrowing and bronchodilation to deep inspiration in bronchial segments from subjects with and without reported asthma. J Appl Physiol 2013;114:1460-71.

25. Wang KCW, Le Cras TD, Larcombe AN, Zosky GR, Elliot JG, James AL, Noble PB. Independent and combined effects of airway remodelling and allergy on airway responsiveness. Clin Science 2018;132:327-38.

26. McParland BE, Macklem PT, Paré PD. Airway hyperresponsiveness: From molecules to bedside. Invited review: airway wall remodelling: friend or foe? J Appl Physiol 2003;95:426-34.

27. Niimi A, Matsumoto H, Takemura M, Ueda T, Chin K, Mishima M. Relationship of airway wall thickness to airway sensitivity and airway reactivity in asthma. Am J Respir Crit Care Med 2003;168:983-8.

28. Brightling CE, Bradding P, Symon FA, Holgate ST, Wardlaw AJ, Pavord ID. Mast cell infiltration of airway smooth muscle in asthma. N Engl J Med 2002;346:1699-705. 29. de Blick J, Tillie-Leblond I, Tonnel AB, Jaubert F, Scheinmann P, Gosset P. Difficult asthma in children: analysis of airway inflammation. J Allergy Clin Immunol 2004;113:94-100.

30. Bossley CJ, Fleming L, Gupta A, Regamey N, Frith J, Oates T, Tsartsali L, Lloyd CM, Bush A, Saglani S. Pediatric severe asthma is characterized by eosinophilia and remodeling without TH2 cytokines. J Allergy Clin Immunol 2012;129:974-82. 
Table 1. Demographics of the 49 patients.

$n=49$

Age, years

$1,06(0,6 ; 1,5)$

Gender, male

$41(84)$

Weight, kg

$10,4(9,2 ; 11,8)$

Height, cm

$76,3(70,6 ; 82,1)$

Asthma

Family

$29(60)$

Parental

$23(48)$

Sibling

$13(27)$

Allergy

Family

$40(83)$

Parental

38 (79)

Sibling

$16(33)$

Tobacco smoking

Both parents

17 (35)

Mother

$12(26)$

Father

$12(26)$

Symptoms

Wheeze

49 (100)

Cough

23 (47)

Dyspnea

$9(18)$

Other

$6(12)$

Duration, months (mean, SD)

$10(7,5)$

While exercising

$36(80)$

Doctor diagnosed wheeze episodes (mean, range)

$2(1-11)$

Hospital admissions

$10(20)$

This article is protected by copyright. All rights reserved 
Treatment prior the study visit

Inhaled B2-agonist, during the last two months

$43(88)$

Antimicrobials, during the last two months

Antimicrobials, ever

$39(80)$

Skin Prick Test

Any positive

$13(27)$

Inhalation allergen

$5(10)$

Food allergen

Clinical findings

Atopic eczema

$16(32)$

Abnormal lung auscultation

Abnormal troracic X-ray

$13(27)$

The results are presented in numbers of individuals (\%) if nothing else stated.

$\mathrm{IQR}=$ Interquartile range; $\mathrm{SD}$ = standard deviation

Table 2. Lung function and laboratory test results

$n=49$

$\mathrm{FRC}(\mathrm{ml})$

$210(176 ; 267)$

FRC (z-score)

$0,2(-0,5 ; 1,1)$

sGaw $\left(\mathrm{kPaL}^{-1} \mathrm{~s}^{-1}\right)$

$1,6(1,1 ; 2,7)$

sGaw (z-score)

$-2,4(-3,50 ; 0,05)$

$V^{\prime} \max F R C(\mathrm{ml} / \mathrm{s})$

$161(105 ; 208)$

V'maxFRC (z-score)

$-1,5(-2,3 ;-0,5)$

Methacholine $\mathrm{PD}_{40} \mathrm{~V}^{\prime}{ }_{\max \mathrm{RC}}, \mathrm{mg}(\mathrm{n}=38)$

$0,44(0,20 ; 0,90)$

This article is protected by copyright. All rights reserved 
PD40 > 0,9 mg

$10(26 \%)$

PD40 >0,45 $\mathrm{mg} \leq 0,9 \mathrm{mg}$

$10(26 \%)$

PD40 >0,21 $\mathrm{mg} \leq 0,45 \mathrm{mg}$

$9(24 \%)$

PD40 $\leq 0,21 \mathrm{mg}$

$9(24 \%)$

Oxygen saturation, pre provocation (\%)

$97(96 ; 99)$

Oxygen saturation, post provocation (\%)

$94(93 ; 95)$

B-eosinophils (10E9/L)

$0,29(0,16 ; 0,41)$

B-eosinophils (\%)

$3,0(2,0 ; 4,0)$

$\mathrm{S}-\lg \mathrm{E}(\mathrm{kU} / \mathrm{I})$

$20,5(7,8 ; 52,3)$

Data presented as median (interquartile range) or $n(n \%)$.

$F R C=$ functional recidual capacity; sGaw = specific airway conductance;

$V^{\prime} \max F R C=$ maximal airflow at FRC; $P D=$ provocative dose

This article is protected by copyright. All rights reserved 
Table 3. Remodeling and inflammatory cell findings in carinal biopsies

$n=49$

RBM (um)

$4,0(3,6 ; 4,4)$

ASM area/subepithelial area (\%)

$10,6(5,3 ; 16,9)$

Mast cells/subepithelial area $\mathrm{mm}^{2}$

$117(77 ; 177)$

Mast cells in ASM /ASM area $\mathrm{mm}^{2}$

$39(11 ; 70)$

Macrophages/subepithelial area $\mathrm{mm}^{2}$

$255(133 ; 381)$

$\mathrm{T}$ cells/subepithelial area $\mathrm{mm}^{2}$

$705(382 ; 1129)$

B cells/subepithelial area $\mathrm{mm}^{2}$

$156(52 ; 321)$

Plasma cells/subepithelial area $\mathrm{mm}^{2}$

$168(72 ; 179)$

Eosinophils/subepithelial area $\mathrm{mm}^{2}$

$0(0 ; 1,3)$

Neutrophils/subepithelial area $\mathrm{mm}^{2}$

$80(47 ; 163)$

Data presented as median (interquartile range).

This article is protected by copyright. All rights reserved 


\section{Figure legends}

Figure 1. A) Maximal airflow at functional residual capacity (V'maxFRC) correlates significantly with airway responsiveness determined by the provocative dose of methacholine causing a 40\% fall in V'maxFRC (PD40 V'maxFRC) $(r=0.394, p=0.047$; Spearman). B) V'maxFRC was not significantly lower among the most reactive quartile (PD40 V'maxFRC $\leq 0.21 \mathrm{mg}$ methacholine) compared to the rest of the children.

Figure 2. A) The percentage of median bronchial airway smooth muscle (ASM) \% in subepithelial area was higher in children with airway hyperresponsiveness (AHR) (PD40 $V$ 'maxFRC $\leq 0.21 \mathrm{mg}$ methacholine) although it did not reach the level of statistical significance ( $p=0.056$; t-test). B) No significant association between ASM $\%$ and AHR was found even when the airway responsiveness was split in quartiles $(p=0.071$; ANOVA, trend test). Children with both atopy (triangle) and increased AHR (the most reactive quartile) had thicker ASM area than non-atopics with increased AHR ( $p=0.031$; KruskallWallis). C) Thickness of reticular basement membrane (RBM) did not correlate with AHR $(p=0.61 ; t$-test). D) The number of bronchial mast cells in ASM did not correlate with AHR (PD40 V'maxFRC $\leq 0.21 \mathrm{mg}$ methacholine) $(\mathrm{p}=0.056$; t-test).

$\mathrm{Q}$, quartile; A triangle stands for atopy.

Figure 3. The association of bronchial eosinophils with maximal airflow at functional residual capacity (V'maxFRC) is significant $(r=-0.318, p=0.029$; Spearman). The asterix refers to three outliers (eosinophils 188.2, 46.4 and 16.3 / subepithelial area $\mathrm{mm}^{2}$ ) for whom the number of eosinophils has been changed to 7 eosinophils / subepithelial area $\mathrm{mm}^{2}$. 


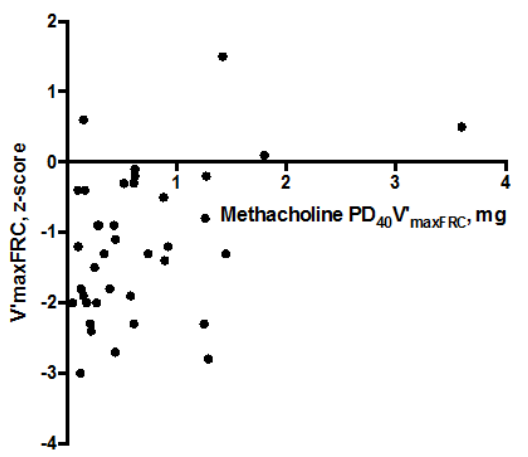

FIG 1A

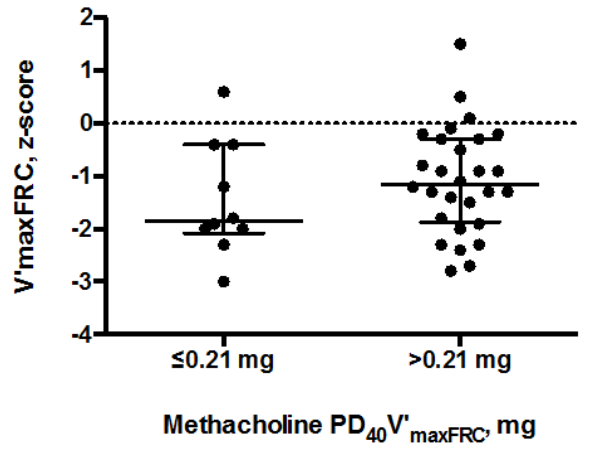

FIG 1B

This article is protected by copyright. All rights reserved 


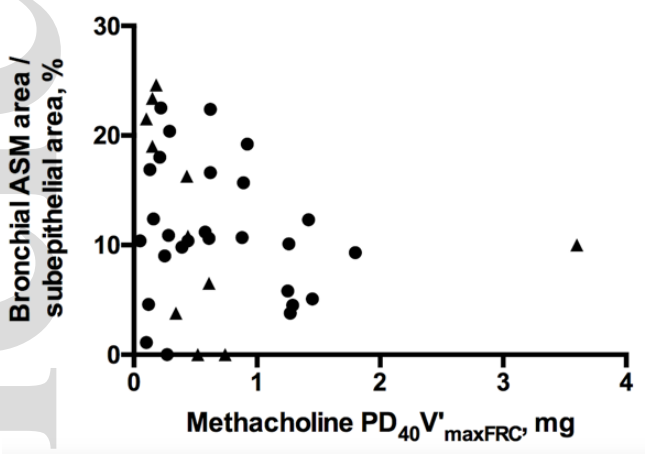

FIG 2A

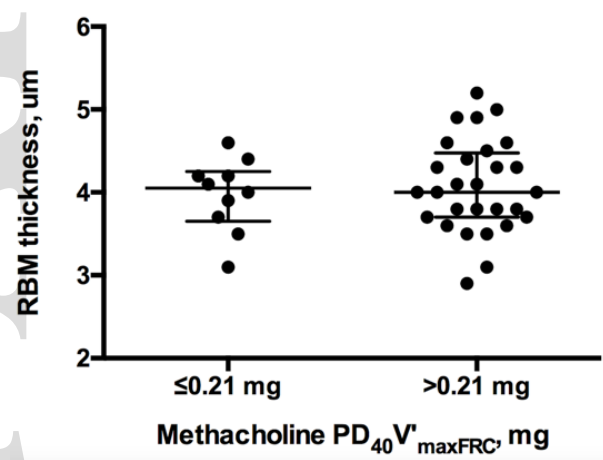

FIG 2C

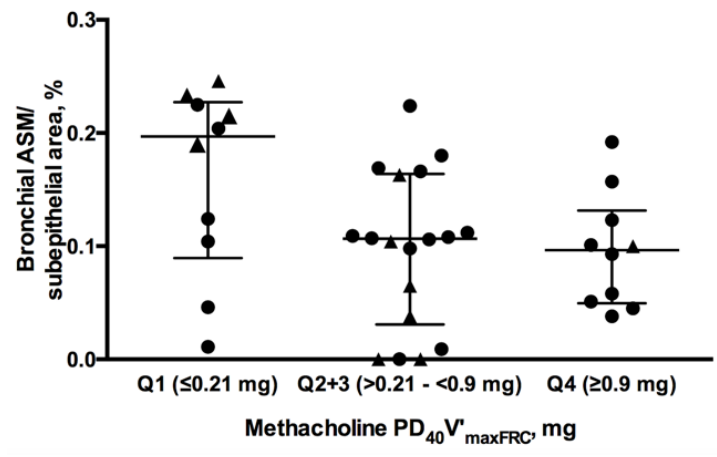

FIG 2B

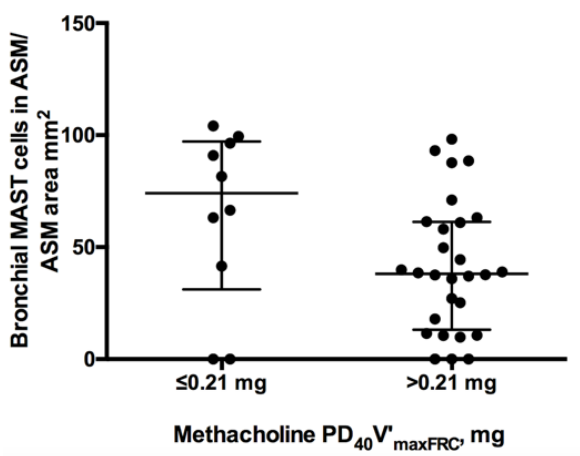

FIG 2D

This article is protected by copyright. All rights reserved 


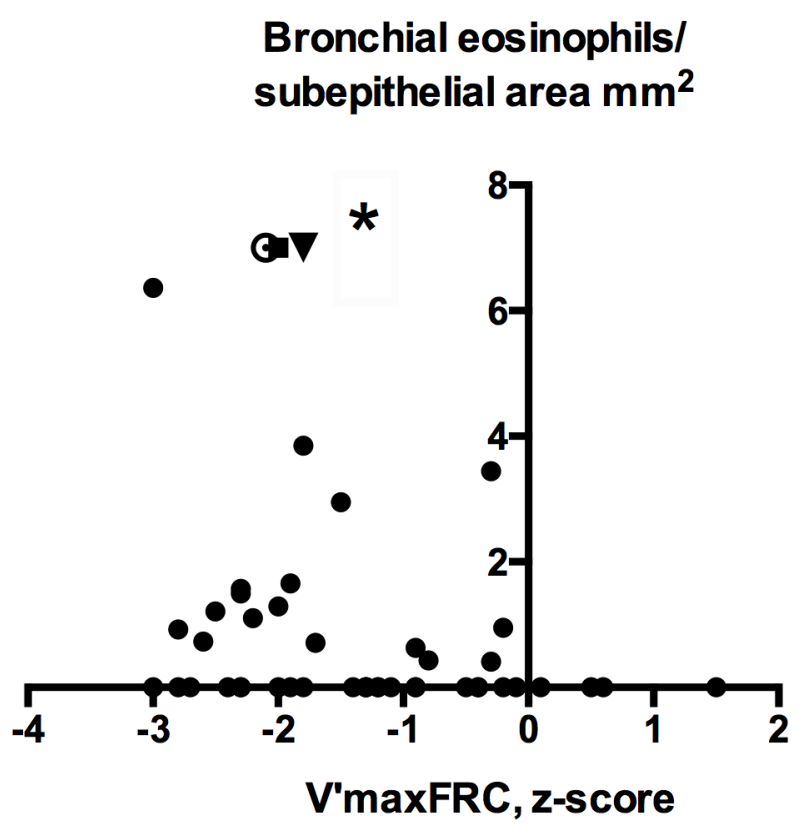

cea_13598_f3.tiff

This article is protected by copyright. All rights reserved 